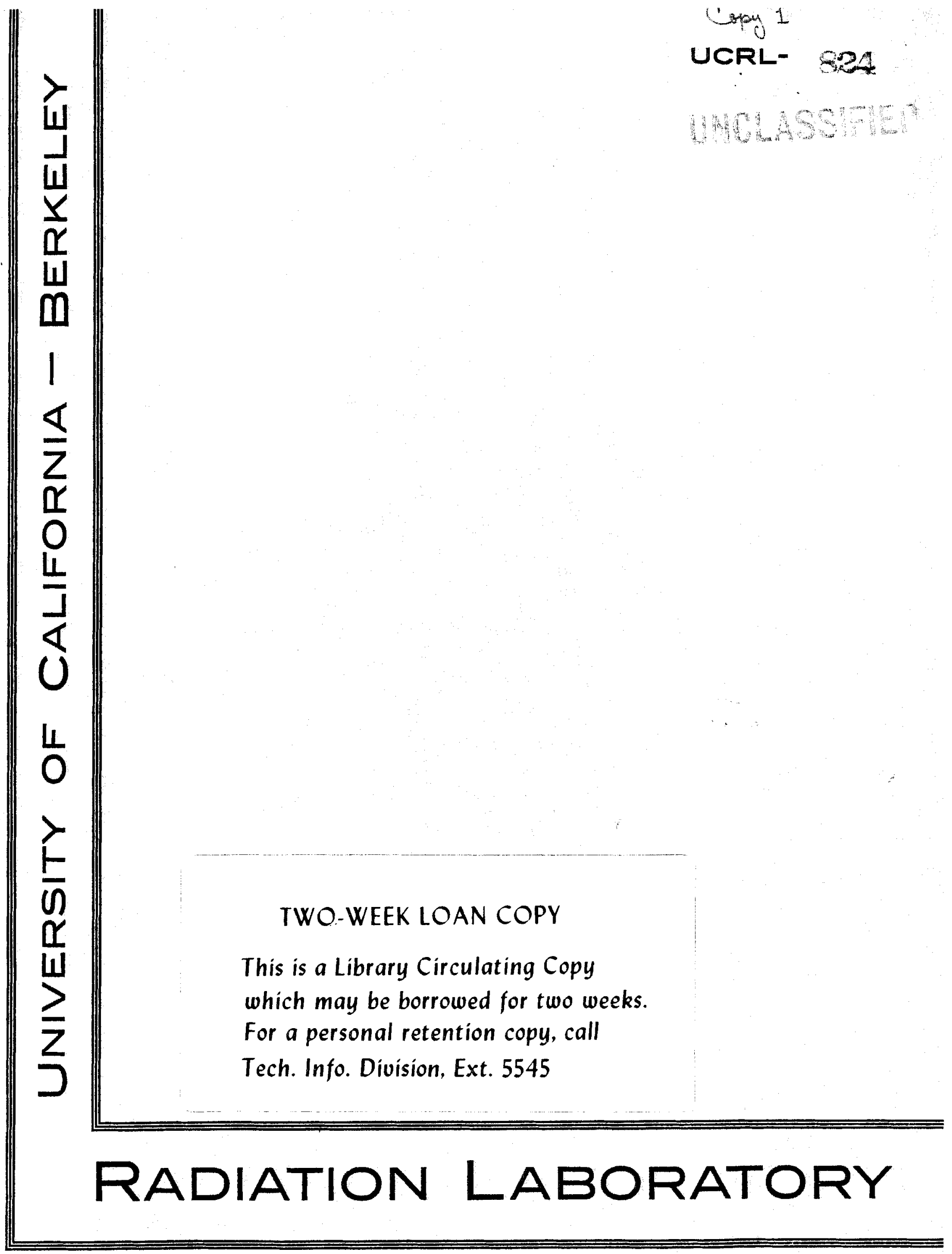


U. S. Army, Atomic Energy Branch (It. Col. A. W. Betts)

1

U. S. Army, Army Field Forces (Captain James Kerr)

U. S. Army, Commanding General, Chemical Corps Technical Command (Col. John A. Maclaughlin thru Mrs. Georgia S. Benjamin)

U. S. Army, Chief of Ordnance (It, Col. A. R. Del Campo)

1

1

$U_{0}$ S. Army, Commanding officer, Watertown Arsenal (Col. Carroll H: Deitrick)

J. S. Army, Director of Operations Research (Dr. Ellis Johnson)

U. S. Army, Office of Engineers (Allen O'Leary)

U. S. Army, Office of the Chief Signal officer (Curtis T. Clayton thru Maj. Ceorge C. Hunt) I

U. S. Army, Office of the Surgeon General (Cól. W. S. Stone)

U. S. Geological Survey (T. B. Nolan) USAF, Director of Plans and Operations (Col. R.L. Applegate) 1 U. S. Public Health Service

University of California at Los Angeles

University of California Radiation Laboratory

University of Rochester

University of Washington

Western Reserve University

Westinghouse Electric Company

Naval Medical Research Institute

* University of Rochester majed to (Minchioh California Institute of Technology (R. F. Bacher)

TOTAL

Information Division

Radiation Laboratory

University of California

Berkeley, California 
UCRL-824

Unclassified Distribution

UNIVERSITY OF CAIIFORNIA

Radiation Laboratory

Contract No. $\mathrm{m}-7405-\mathrm{eng}-48$

PAPER CHPOMATOGRAPHY OF STEROIDS

David Kritchevsky and M.Calvin

July 28, 1950

Berkeley, California 
Argonne National Laboratory

Armed Forces Special Weapons Project

Atomic Energy Commission - Washington

Battelle Memorial Institute

Brush Beryllium Company

Brookhaven National Laboratory

Bureau of Medicine and Surgery

Bureau of Ships

Carbide and Carbon Chemicals Division (K-25 Plant)

Carbide and Carbon Chemicals Division ( $Y-12$ Plant)

Chicago Operations office

Columbia University (J. R. Dunning)

Columbia University (G. Failla)

Dow Chemical Company

H. K. Ferguson Company

General Blectric, Richland

Harshaw Chemical Corporation

Idaho Operations office

Iowa State College

Kansas City Operations Branch

Kellex Corporation

Knolls Atomic Power Laboratory

Ios Alamos Scientific Laboratory

Mallinckrodt Chemical Torks

Massachusetts Institute of Technology (A, Gaudin)

Massachusetts Institute of Technology (A. R. Kaufmann)

Mound Laboratory

National Advisory Committee for Aeronautics

National Bureau of Standards

Naval Radiological Defense Laboratory

New Brunswick Laboratory

New York Operations Office

North American Aviation, Inc.

Oak Ridge National Laboratory

Patent Branch (Washington)

Rand Corporation

Sandia Corporation

Santa $F e$ Operations Office

Sylvania Electric Products, Inc.

Technical Information Division (Oak Ridge)

USAF, Air Surgeon (It. Col. R. H, Blount)

USAF, Director of Armament (Captain C. I. Browne)

USAF, Director of Research and Development

(Col. R. J. Mason, Fred W. Bruner)

USAF, Eglin Air Force Base (Najor A. C. Field)

USAF, Kirtland Air Force Base (Col. Marcus F. Cooper)

USAF, Maxwell Air Force Base (Col. F. N. Moyers)

USAF, NEPA Office

USAF, Office of Atomic Energy (Col.H.C. Donelly, A.A. Fickel)

USAF, Offutt Air Force Base (Col. H. R. Sullivan, Jr.)

USAF, Wright-Patterson Air Force Base (Rodney Nudenberg) 


\title{
PAPER CHROMATOGRAPHY OF STEROIDS
}

David Kritchevsky and M. Calvin

\section{Radiation Laboratory and Department of Chemistry, University of California, Berkeley (*)}

\author{
ABSTRAC世 \\ July 28, 1950
}

A method for the paper chromatography of sterols involving impregnated paper has been developed.

For publication in The Journal of the American Chemical Society

(*) The work described in this paper was sponsored by the Atomic Energy Commission. 


\section{$-4-$}

UGRI-824

PAER CHROMATOGRAPHY OF STEROIDS ${ }^{1}$

David Kritchevsky and M. Calvin

Radiation Laboratory and Department of Chemistry, University of California, Berkeley, California

The separation of cholesterol and cholestenone has been achieved by using paper impregnated with "Quilon ${ }^{N 2}$ as the stationary phase and simple primary alcohols as solvents. In effect, the stationary phase consists of the stearic acid residues,

Use of paper impregnated with rubber latex ${ }^{3}$, silicic acid and alumina ${ }^{4}$ in paper chromatography has been reported. Of these, alumina paper was tried and found to give erratic results. The method of Zaffaroni and co-workers 6 for the paper chromatography of steroids using peper saturated with formamide

(I) The work described in this paper was sponsored by the Atomic Energy Commission。

(2) Stearato chromic chloride, generously supplied by E. I. duPont de Nemours and Compeny Ine. $^{2}$

(3) Boldingh, Experientia \& 270 (1948).

(4). Kirchner and Keller, Jo Am. Chem。Soc.s 72,1867 (2950).

(5) Datta and OvereII, Biochem。 Jog 44 xliii (1949).

(6) Zaffaroni, Burton and Keutmann, Science, 111, 6 (1950). 
or propylene glycol as the stationary phase and a hydrocarbon solvent walso tried. In these experiments the sterolds were found to move with the front. Using ordinary paper ( Whatman No. 1), cholesterol was found either to move with the solvent front or remain at the arigin.

For ease of location, tritiated cholesterol was used and the material Iocated by scaming the paper with a windowless counting tube designed to Iocate weakly radiating substances on papers.

The presence of cholesterol at the points of high activity was confirmed by the red color developed fter papers tregted with solution of silicotungstic acid wer aried. Cholestenone gave an olive green color with this reagent, but only when the steroid was present in relatively large amounts. Cholestenone was most easily detected by the yellow color obtained with a reagent consisting of a solution of lodine and patassium iodide in water'.

The most satisfactory solvents, to date, have been methanol, ethanol, and sthanol-water 8:2。 The latter solvent gives the best separation of cholesterol and cholestenone。 The results are tabulated below.

Table 1

$\begin{array}{lcc}\text { Solvent } & \left.\text { Cholesterol ( } \mathrm{R}_{\mathrm{f}}\right) & \text { Cholestenono (Rf) } \\ \text { Methanol } & 0.56 & 0.77 \\ \text { Ethanol } & 0.92 & 0.97 \\ \text { 80\% Ethanol } & 0.52 & 0.86\end{array}$

(7) Gray, Ikeda, Benson and Kritchevsky, Rev。 Sci.Inst, in press.

(8) Montignie, Bu11. s0c。 chim, 51,690 (2932).

(9) Munier and Macheboeuf Bull, soc。chim. Biol。g 3I, 1144 (1949). 


$$
-6-\quad \text { JCRL }-824
$$

All experiments were carried out as descending chromatograms using $1-1 / 2^{n} \times 15^{n}$ strips of the impregnated paper. The paper was usually wot to a distance of about $25 \mathrm{~cm}$. from the origin. $\mathbb{R}_{f}$ values were measured from the farthest point of the origin and the foremost point of the colored or active zone.

Projected work includes widening the range of usable solvents, development of supplementary color reactions and extension of this method to other steroids.

\section{SUMMARY}

A method for the paper chromatography of sterols involving impregnated paper has been developed. 